Article

\title{
Reduction of Friction of Metals Using Laser-Induced Periodic Surface Nanostructures
}

\author{
Zhuo Wang ${ }^{1}$, Quanzhong Zhao ${ }^{1,2, *}$ and Chengwei Wang ${ }^{2}$ \\ Received: 21 August 2015 ; Accepted: 20 October 2015 ; Published: 28 October 2015 \\ Academic Editor: Maria Farsari \\ 1 School of Materials Science and Engineering, Shanghai Jiao Tong University, Shanghai 200240, China; \\ shangjiaobao@sjtu.edu.cn \\ 2 State Key Laboratory of High Field Laser Physics, Shanghai Institute of Optics and Fine Mechanics, \\ Chinese Academy of Sciences, Shanghai 201800, China; wangchengwei@siom.ac.cn \\ * Correspondence: zqz@siom.ac.cn; Tel.: +86-21-6991-8749
}

\begin{abstract}
We report on the effect of femtosecond-laser-induced periodic surface structures (LIPSS) on the tribological properties of stainless steel. Uniform periodic nanostructures were produced on AISI 304L (American Iron and Steel Institute steel grade) steel surfaces using an 800-nm femtosecond laser. The spatial periods of LIPSS measured by field emission scanning electron microscopy ranged from 530 to $570 \mathrm{~nm}$. The tribological properties of smooth and textured surfaces with periodic nanostructures were investigated using reciprocating ball-on-flat tests against AISI $440 \mathrm{C}$ balls under both dry and starved oil lubricated conditions. The friction coefficient of LIPSS covered surfaces has shown a lower value than that of the smooth surface. The induced periodic nanostructures demonstrated marked potential for reducing the friction coefficient compared with the smooth surface.
\end{abstract}

Keywords: femtosecond laser; laser-induced periodic surface structures; tribological properties; stainless steel

\section{Introduction}

It is well known that surface texturing is an effective way of improving tribological properties under both dry and lubricated conditions [1-3]. Its main effect mechanisms are to trap wear particles, store lubricants, and increase load carrying capacity [4-6]. Various surface texturing technologies, such as mechanical machining, lithography, ion beam texturing, and laser texturing [7-10] have been developed for preparing the micrometer-sized features on the surface of materials. Among these techniques, femtosecond laser surface texturing seems to be the most advanced method of surface texturing for tribological applications. Its effectiveness can be attributed to its ultrashort pulse width and ultrahigh peak power that can safely process almost all material with minimal heat effects [11-13].

Recently, laser-induced periodic surface structures (LIPSS) have gained remarkable interest because they enable tuning of a wide range of properties, including wettability [14], colorization [15], and tribological properties [16-18]. LIPSS or so-called ripples have been observed on numerous solid material surfaces. As early as 1965, LIPSS were first observed by M. Birnbaum on semiconductor surfaces using a ruby laser [19]. With the development of laser technology, ripples can now be induced by different lasers with varied wavelengths and pulse widths. In general, LIPSS with periods close to the laser wavelength are called low spatial frequency LIPSS (LSFL), while LIPSS with periods much smaller than the laser wavelength are referred to as high spatial frequency LIPSS (HSFL) [20-30]. Several mechanisms have been proposed to explain the formation mechanisms of LIPSS, such as interference mechanisms [31], excitation of surface plasmon polaritons [32], 
self-organization [33], second harmonic generation [34], and Coulomb explosion [35]. However, some issues still need to be clarified.

As mentioned above, LIPSS exhibit several amazing properties such as the capability of tuning wettability, reflectivity, and tribological properties. The modification of tribological properties has specifically attracted attention because of its potential application in industrial fields. Yasumaru et al. [12] reported that the frictional properties of diamond-like carbon (DLC) films are greatly improved by the coating of a $\mathrm{MoS}_{2}$ (molybdenum disulfide) layer on the LIPSS. However, Eichstädt et al. [17] reported an increased friction coefficient of LIPSS-covered silicon for normal loads in the $\mathrm{mN}$ range. Recently, Bonse et al. [18] studied the effects of the LIPSS of steels on the friction coefficient under lubricated conditions. The results indicated that the LIPSS of the steel did not significantly reduce the friction coefficient compared with smooth surface (no LIPSS) under lubricated condition. Consequently, we consider it necessary to further investigate the effects of the LIPSS of steels on tribological properties under both dry and lubricated conditions. Moreover, the mechanisms for the effect of LIPSS on tribological properties are still not clear and require further investigation.

In this study, textured surfaces with uniform LIPSS were fabricated using a femtosecond laser on AISI 304L (American Iron and Steel Institute steel grade) steel surfaces. The effects of LIPSS on the tribological properties were investigated by performing reciprocating ball-on-flat tests against AISI 440C (American Iron and Steel Institute steel grade) steel balls under both dry and lubricated conditions. The friction coefficient of AISI 304L steel with LIPSS was observed to be remarkably reduced for both the dry and lubricated conditions. Our findings may suggest applications in fields including magnetic storage and microelectromechanical systems (MEMS).

\section{Experimental Procedures}

AISI 304L stainless steel prepared by Taiyuan Stainless Steel Co., Ltd. (Tiayuan, China) was used as the experimental material. The density, Young's modulus, Poisson's ratio, and hardness of this material were $7.93 \mathrm{~g} \cdot \mathrm{cm}^{-3}, 203 \mathrm{GPa}, 0.28$ and $198 \mathrm{HV}$, respectively. Those same measurements for the friction test material, an AISI 440C steel ball, were $8.65 \mathrm{~g} \cdot \mathrm{cm}^{-3}, 200 \mathrm{GPa}, 0.3$ and $720 \mathrm{HV}$, respectively. Plane AISI 304L steel samples with dimensions of $25 \mathrm{~mm} \times 15 \mathrm{~mm} \times 6 \mathrm{~mm}$ were cut from the as-received stainless steel plates. Before surface texturing, the plane steel samples were ground and polished to a mirror finish using a $0.5-\mu \mathrm{m}$ diamond polishing agent produced by Shanghai Metallurgical Equipment Co., Ltd. (Shanghai, China). The final surface roughness $R_{a}$ before texturing was $0.05 \pm 0.005 \mu \mathrm{m}$ (smooth surface). However, polished surfaces with different roughness value were inevitable in the process of polishing. In order to avoid experimental error, we selected the samples with almost the same surface roughness. Surface roughness was measured using a scanning probe microscope (SPM, Bruker, Multimode 8, Camarillo, CA, USA). The AISI 440C steel balls provided by USA CETR Company (Campbell, CA, USA) had a diameter of $3.969 \mathrm{~mm}$, and their surface roughness was less than $R_{a}=0.02 \mu \mathrm{m}$.

The plane steel samples were mounted on a xyz mobile stage (Prior, Proscan II, Rockland, MA, USA) with a resolution of $1 \mu \mathrm{m}$, which was precisely computer controlled by the Visual Basic 6.0 software (Microsoft, Redmond, WA, USA) for laser micromachining in Figure 1. A regeneratively amplified 800-nm Ti: sapphire laser emitting a train of 130-fs, 1-kHz mode-locked pulses was used for the laser surface texturing. A rotary $\lambda / 2$ wave plate was placed in the optical path to produce horizontally polarized laser pulses. In front of the $\lambda / 2$ wave plate, a continuously variable reflective neutral density filter was used to modify the power of the laser pulses. Some reflective mirrors placed in the optical path were used to guide the laser beam toward the sample surfaces. In order to produce uniform LIPSS, we optimized the laser parameters and selected a pulse energy of $0.4 \mu \mathrm{J}$, which was focused via a microscope objective $(10 \times, N A=0.3)$ to give a spot size of about $10 \mu \mathrm{m}$ on the plane steel surfaces. The laser fluence on the target was estimated to be $0.36 \mathrm{~J} / \mathrm{cm}^{2}$. The stainless steel sample was translated at a constant speed of $200 \mu \mathrm{m} / \mathrm{s}$, where the parallel scan of the focal spot with a period 
of $5 \mu \mathrm{m}$ (50\% overlap) was made to produce a uniformly nanostructured surface over an area of $6 \mathrm{~mm} \times 6 \mathrm{~mm}$ [12].

The surface topographies of the femtosecond laser surface textured surfaces were measured using a scanning probe microscope (SPM, Bruker, Multimode 8). The surface morphologies were imaged using a field emission scanning electron microscope (SEM, JEOL, JSM-7600F, Tokyo, Japan).

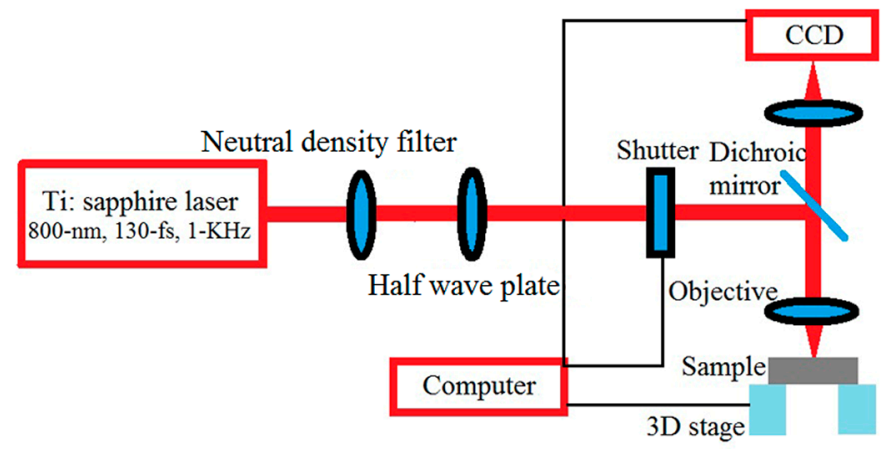

Figure 1. The schematic diagram of the femtosecond laser processing procedure.

Reciprocating ball-on-flat tests were executed using a tribometer (CETR, UMT-2, Campbell, CA, USA) according to the ASTM (American Society for Testing and Materials) G133 standard to investigate the friction and wear behavior of the textured and smooth AISI 304L surfaces sliding against AISI 440C balls. The AISI 304L stainless steel surfaces were mounted on the flat surfaces, and the AISI $440 \mathrm{C}$ balls fixed on a fixture reciprocated the surfaces at a speed of $5 \mathrm{~mm} / \mathrm{s}$. The smooth surface (polished surface) is named SS in this study. For LIPSS-90 and LIPSS-0, the orientations of the ripple structures were perpendicular and parallel to the sliding direction of the ball sample, respectively. For each test, the stroke length was $5 \mathrm{~mm}$, and the normal load was $2 \mathrm{~N}$. The tests were performed at room temperature, $25 \pm 1{ }^{\circ} \mathrm{C}$, with $30 \% \pm 1 \%$ relative humidity. Before each test, the balls and surfaces were cleaned in acetone and ethanol and blown dry with nitrogen to remove residual dust, grease, and other solid contaminants to keep the surface conditions as constant as possible. The worn areas of the surfaces were examined using an SEM.

The lubricant used in the tests was Priolube 3959 (Croda, Yorkshire, UK), and its dynamic viscosity was $7.7 \mathrm{~Pa} \cdot \mathrm{S}$ at $40^{\circ} \mathrm{C}$. Before each test, the lubricant was daubed on the contact surface, and only a thin layer of lubricant remained on the surface [36].

The friction coefficient as a function of time was directly determined using the software on the UMT-2 tribometer. Then, the average friction coefficients were calculated based on the average values in the stage of the stable curve in order to evaluate the friction property of the tested samples. The final test result was the mean value of six tests, including one standard error of mean.

\section{Results and Discussion}

\subsection{Laser Induced Periodic Surface Structures (LIPSS) of AISI 304 Steel}

SEM micrographs of the femtosecond-laser-induced periodic surface structures are presented in Figure 2. From Figure 2a,b, it can be seen that uniform ripple structures are produced on the textured surface. Figure $2 \mathrm{c}$ illustrates that the ripple structures are oriented in the direction perpendicular to the laser polarization direction. The mean spacing in the ripple structures was measured to be $550 \pm 3.3 \mathrm{~nm}$ along the polarization direction, which is less than the wavelength of the femtosecond laser pulses. The ripple structure studied in this paper is thus known as low spatial frequency laser-induced periodic surface structure (LSFL) [37]. As mentioned above, the formation mechanism of LIPSS is still in debate and some issues need to be further investigated [30-35,37]. Figure 3 shows the surface topography and the cross-sectional surface line profile of the ripple structures on the AISI 304L steel surfaces. The horizontally arranged ripple structures are shown in Figure 3a. Figure 3b 
shows that the surface undulation of ripple structures is $235 \pm 3.6 \mathrm{~nm}$. The measurements of spacing and undulation of ripple structures were repeated 10 times to obtain a reliable data set.

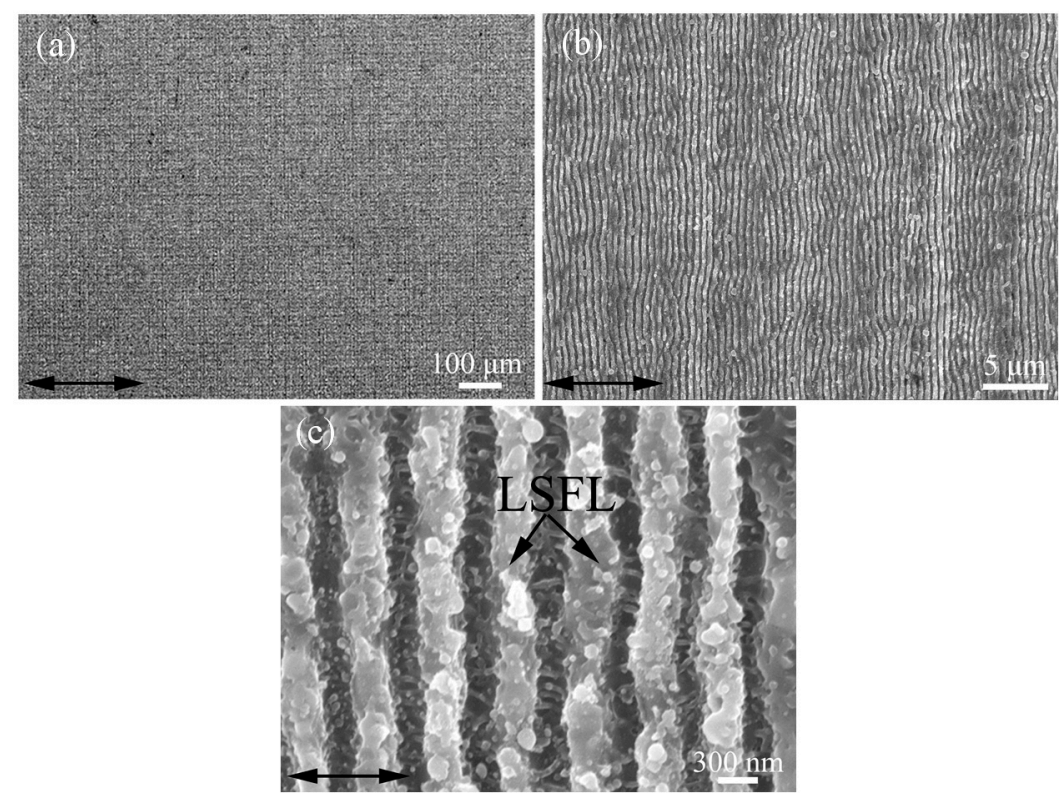

Figure 2. SEM (scanning electron microscope) micrographs of the LIPSS (laser-induced periodic surface structures) on the AISI (American Iron and Steel Institute) 304L steel surfaces. Note the different magnifications used in $(\mathbf{a}-\mathbf{c})$. The black double-headed arrow indicates the polarization direction of the femtosecond laser pulses.

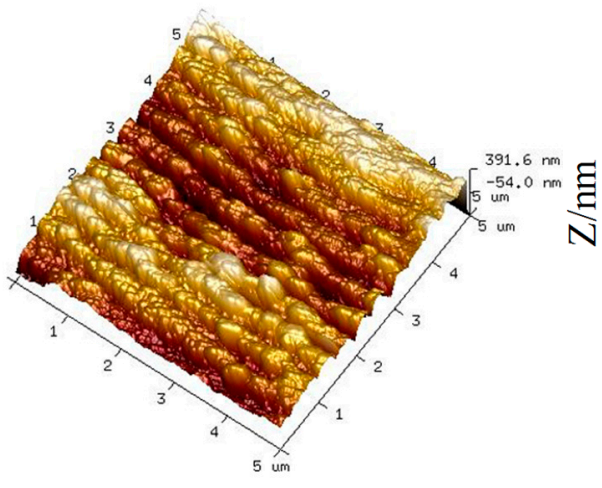

(a)

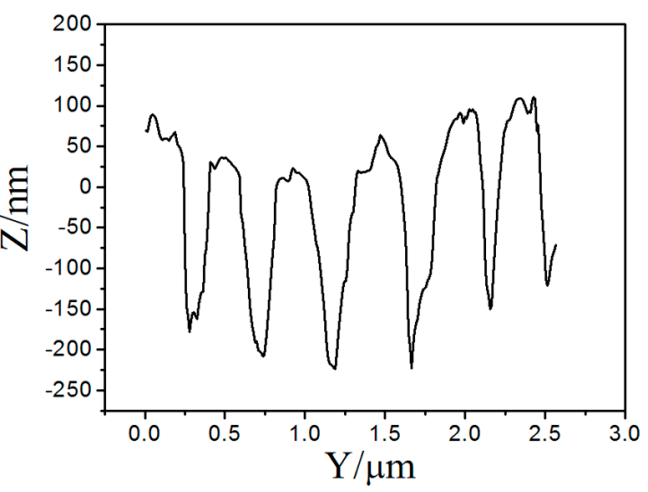

(b)

Figure 3. Surface morphology and cross-sectional surface line profile of the LIPSS on the AISI 304L steel surface. (a) 3-D surface morphology; (b) Cross-sectional surface profile.

\subsection{Effect of LIPSS on Tribological Properties Under Dry Conditions}

Figure 4a presents the friction coefficient curves of the smooth surface $\left(R_{\mathrm{a}}=0.05 \pm 0.005 \mu \mathrm{m}\right)$ and textured surfaces with LIPSS under dry conditions. For LIPSS-90 and LIPSS-0, the orientations of the ripple structures are perpendicular and parallel to the sliding direction of the ball sample, respectively. For the textured surfaces (LIPSS-90 and LIPSS-0), the friction coefficient first increases and then tends to become stable with increasing time, which can be explained by the rapid increase in contact area due to higher contact stress on the textured surface. Moreover, the running time of the textured surfaces with LIPSS is approximately $120 \mathrm{~s}$. Whereas the friction coefficient curve of SS is relatively stable in the early stage, which may be attributed to the lower contact stress. It also can 
be observed that the friction coefficient curve of SS and LIPSS-0 is almost stabilized in the range from 0.32 to 0.36 with the passage of time. In tests involving the textured surface with LIPSS-90, the friction coefficient finally stabilizes in the range of $0.28-0.32$.

The average friction coefficients were calculated based on average values in the stable stage of the friction coefficient curve in Figure $4 \mathrm{~b}$. The results indicate that the average friction coefficient of the SS is $0.343 \pm 0.010$. The average friction coefficient of LIPSS-0 is slightly lower than that of the SS. However, the average friction coefficient of LIPSS-90 is $0.292 \pm 0.009$, which represents a reduction of $14.9 \%$ compared with the SS. This phenomenon can be explained by the combined effects of adhesion, trapped wear particles, and asperity deformation. Some researchers have reported that the friction force is generated by adhesion, plowing by wear particles, and asperity deformation under dry condition for metal sliding on metal [38]. Consequently, the friction coefficient is composed of three components and can be formulated by Equation (1).

$$
\mu=\mu_{a}+\mu_{p}+\mu_{d}
$$

where $\mu_{a}$ is the friction coefficient due to the adhesion, $\mu_{p}$ is the friction coefficient due to plowing by wear particles, and $\mu_{d}$ is the friction coefficient due to asperity deformation. The adhesion component $\mu_{a}$ is mainly affected by the contact area of friction pairs and the plowing component $\mu_{p}$ strongly depends on the wear particles. During the friction process, the contact area between LIPSS-90 and LIPSS-0 and the ball sample is reduced due to the ripples compared with SS, which is in line with [41]. Meanwhile, the nanoscale wear particles can be effectively trapped by the textured surfaces with LIPSS [39-41]. The decrease in contact area and trapped effect are beneficial to reducing friction coefficient. From Figure 5, it also can be seen that the plastic deformation of LIPSS-90 and LIPSS-0 is constrained compared with that of SS. The result can also be proved by the relatively smooth wear track of LIPSS-90 and LIPSS-0 compared with that of SS in Figure 5. Consequently, the friction coefficient of LIPSS covered surfaces has shown a lower value than that of the smooth surface.

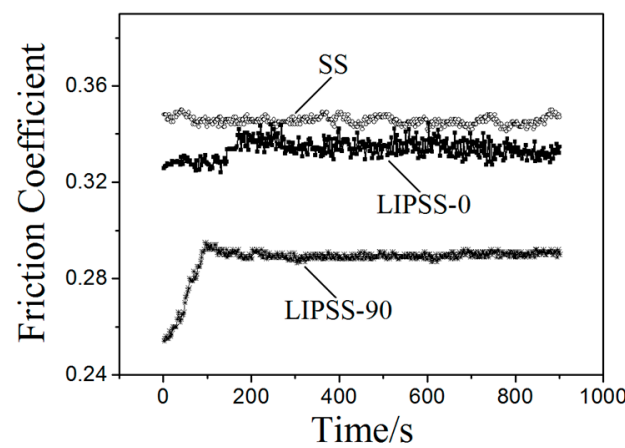

(a)

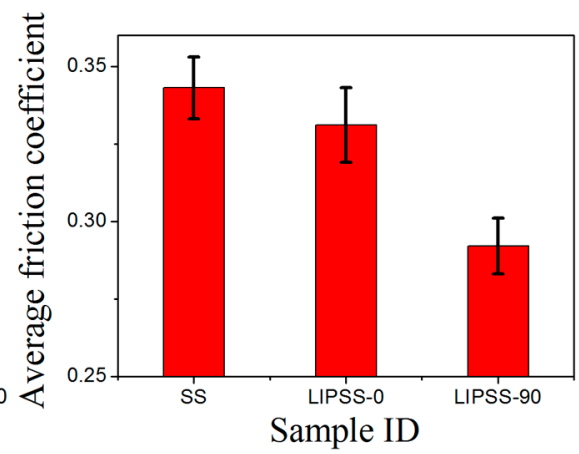

(b)

Figure 4. The results of friction test under the dry condition. (a) Variation of the friction coefficient with time; (b) Average friction coefficient.

Figure 4 shows that the friction coefficient of LIPSS-90 is lower than that of LIPSS-0. The main three components of the friction coefficient have to be taken into consideration when discussing these friction results. There is no obvious difference in contact area of LIPSS-90 and LIPSS-0 because the dimension of ripple structure is much smaller than that of the wear track. With regard to the plowing component, when the sliding direction of the ball sample is perpendicular to the orientation of LIPSS, the wear particles can be effectively trapped by the textured surfaces with LIPSS [41]. However, the wear debris may slide continuously with the movement of the ball sample when the sliding direction of the ball sample is parallel to the orientation of the LIPSS. Consequently, the average friction coefficient of LIPSS-90 is substantially lower than that of the LIPSS-0. The research of Yu et al. [43] also supports the theory demonstrating a lower friction coefficient for LIPSS-90. In this study, the ripple structure can be regarded as a nano-scale grooved-shape texture, and the $b / R$ ratio 
(groove width/radius of ball sample) is about $1 \times 10^{-4}$, which can be correlated with the range of thin grooves. Compared with discontinuous contact between the LIPSS-90 and ball sample, a longer stiction length (the contact length prior to macroslip initiation) exists between the LIPSS-0 and ball sample. Based on the theory of $\mathrm{Yu}$ et al., the shorter stiction length to adhesion results in a lower friction coefficient in the case of LIPSS-90 [42,43].
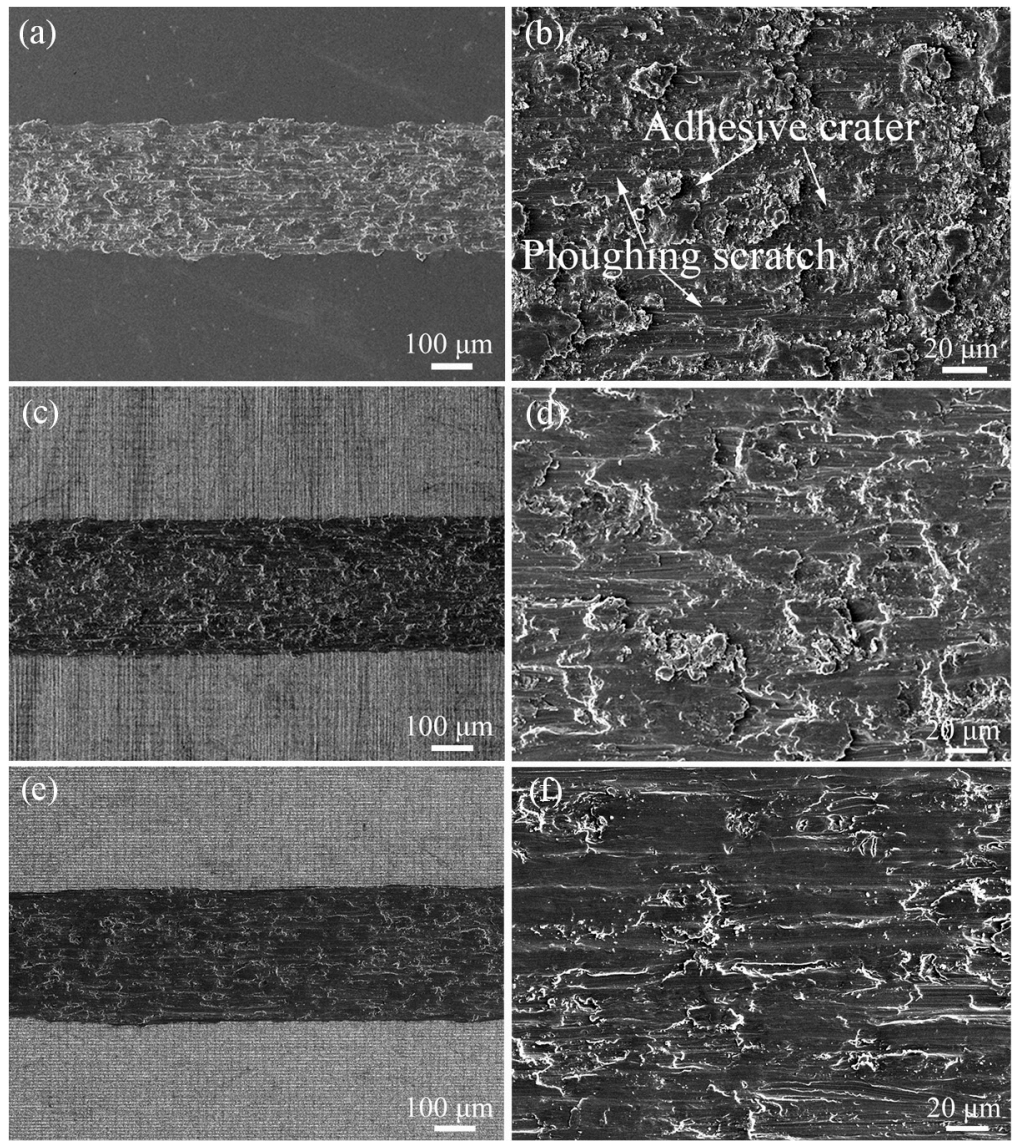

Figure 5. SEM micrographs of the wear tracks under the dry condition. $(\mathbf{a}, \mathbf{b})$ Wear tracks of smooth surface (SS); (c,d) Wear tracks of LIPSS-90; (e,f) Wear tracks of LIPSS-0.

Figure 5a,b present SEM micrographs of the wear track of the smooth surface under dry conditions. For the smooth surface, the width of the wear track is approximately $350 \mu \mathrm{m}$. Adhesive craters and ploughing scratches are observed, indicating that the wear mechanism is mainly adhesive wear and abrasive wear. In addition, obvious plastic deformation and some large wear particles can be observed on the rough wear track surface, which may represent the accumulation of small wear particles and repeated extrusion deformation between the ball and plane sample in the frictional process.

Figure $5 c-f$ present SEM micrographs of the wear track of LIPSS-90 and LIPSS-0 under dry conditions, respectively. The widths of the wear track of the textured surfaces with LIPSS are the same as those for the smooth surface. The large wear particles cannot be observed on the wear track of LIPSS-90 and LIPSS-0, and the wear track surface is relatively smooth in Figures $5 \mathrm{~d}$, $\mathrm{f}$ because of the decrease in contact area and the fact that the small wear particles are trapped by the textured surface with the LIPSS. Therefore, it is difficult for large wear particles to form in the friction process. The plastic deformation of LIPSS-90 and LIPSS-0 is not obvious compared with that of SS. 


\subsection{Effect of LIPSS on Friction Properties Under Starved Oil Lubricated Conditions}

We also investigated the effect of LIPSS on tribological properties under starved lubricated conditions. Figure 6 shows the friction coefficient of the smooth surface (SS) and textured surfaces with LIPSS under starved oil lubricated conditions. LIPSS-90 and LIPSS-0 still represent the orientation of the ripple structures perpendicular and parallel to the sliding direction of the ball sample, respectively. In Figure 6a, the friction coefficient curves of the smooth surface and textured surfaces with LIPSS first fluctuate and then tend to stabilize with time. The friction coefficient of the SS remains stable from 0.12 to 0.16 . In tests involving the textured surfaces with LIPSS (LIPSS-90 and LIPSS-0), the friction coefficient stabilizes at a value between 0.06 and 0.10 . Both LIPSS-90 and LIPSS-0 are observed to play a role in decreasing the friction coefficient under the lubricated condition.

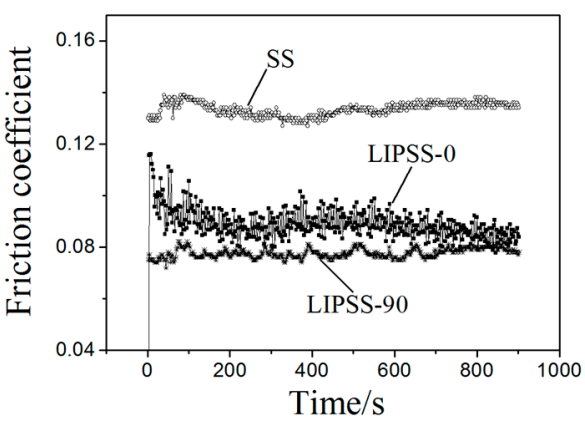

(a)

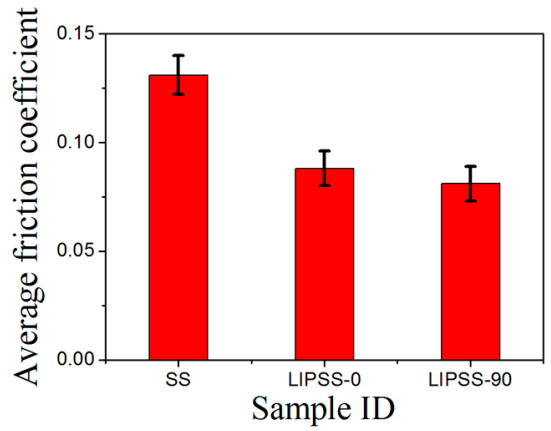

(b)

Figure 6. The results of friction test under the starved lubricated condition. (a) Variation of the friction coefficient with time; (b) Average friction coefficients.

The average friction coefficients were calculated based on the average values in the stable stage of the curve in Figure $6 \mathrm{~b}$. The results indicate that the average friction coefficient of the SS was $0.131 \pm 0.009$. The coefficients for LIPSS-90 and LIPSS- 0 were $0.081 \pm 0.008$ and $0.088 \pm 0.008$, respectively, under the starved oil lubricated condition. These results indicate that the average friction coefficients of the textured surfaces with LIPSS are significantly reduced compared with that of the smooth surface (by $38 \%$ and $33 \%$, respectively). The results also suggest that LIPSS are beneficial to improving the tribological properties compared with the smooth surface under the starved oil lubrication condition. Some researchers believe that the change in the average friction coefficients depends on the combined effects of adhesion, lubricant reservoirs, and deformation under starved oil lubrication conditions [44,45]. In this study, the average friction coefficient of the textured surfaces with LIPSS was lower than that of the smooth surface. The improvement of tribological properties probably benefits from the so-called lubricant reservoirs effect. The lubricant stored in the ripples acts as a secondary source of lubricant and can be drawn into the rubbing surface. Meanwhile, the ripple structures decrease the metallic adhesion between metal friction pairs, which can be attributed to the reduction in contact area between the nano-textured surface and the ball sample. Therefore, the adhesion effect becomes weaker and the friction coefficient is reduced [44,45]. These effects lead to the reduction of the average friction coefficient of the textured surfaces with LIPSS compared with the smooth surface. Figure 7 also shows that the plastic deformation of LIPSS-90 and LIPSS-0 is not obvious compared with that of SS. Consequently, the textured surfaces with LIPSS have marked potential for reducing the friction coefficient under starved lubricated conditions. For both LIPSS-90 and LIPSS-0, the dense textures with LIPSS are within the friction contact area, and the friction contact area frequently passes over the texture with LIPSS, which leads to no obvious difference in friction coefficient between LIPSS-90 and LIPSS-0. In this study, the friction coefficient of LIPSS is lower than that of SS, which is different from the result of Bonse et al. [18]. The difference in ripple structure between this study and Bonse et al. may be the main cause of the different conclusions. 
The different LIPSS parameters such as ripple spatial periods and undulation result in different friction test results to some extent. Moreover, the different friction test conditions also probably lead to different experimental results between this study and Bonse et al. [18].

Figure $7 \mathrm{a}, \mathrm{b}$ present SEM micrographs of the wear track of the smooth surface under the lubricated condition. For the smooth surface, the width of the wear track is approximately $210 \mu \mathrm{m}$. Adhesive craters and ploughing scratches are observed, indicating that the wear mechanisms are mainly adhesive wear and abrasive wear. In addition, large wear particles can be observed on the wear track surface, which may represent the accumulation of small wear particles in the frictional process.

Figure 7c-f present SEM micrographs of the wear track of the textured surface with LIPSS under the lubricated condition. The large wear particles are not observed on the wear track's surface because of the decrease in contact area. Therefore, it is difficult for large wear particles to form in the frictional process compared with SS. The obvious plastic deformation cannot be found in the wear track morphologies of LIPSS-90 and LIPSS-0.
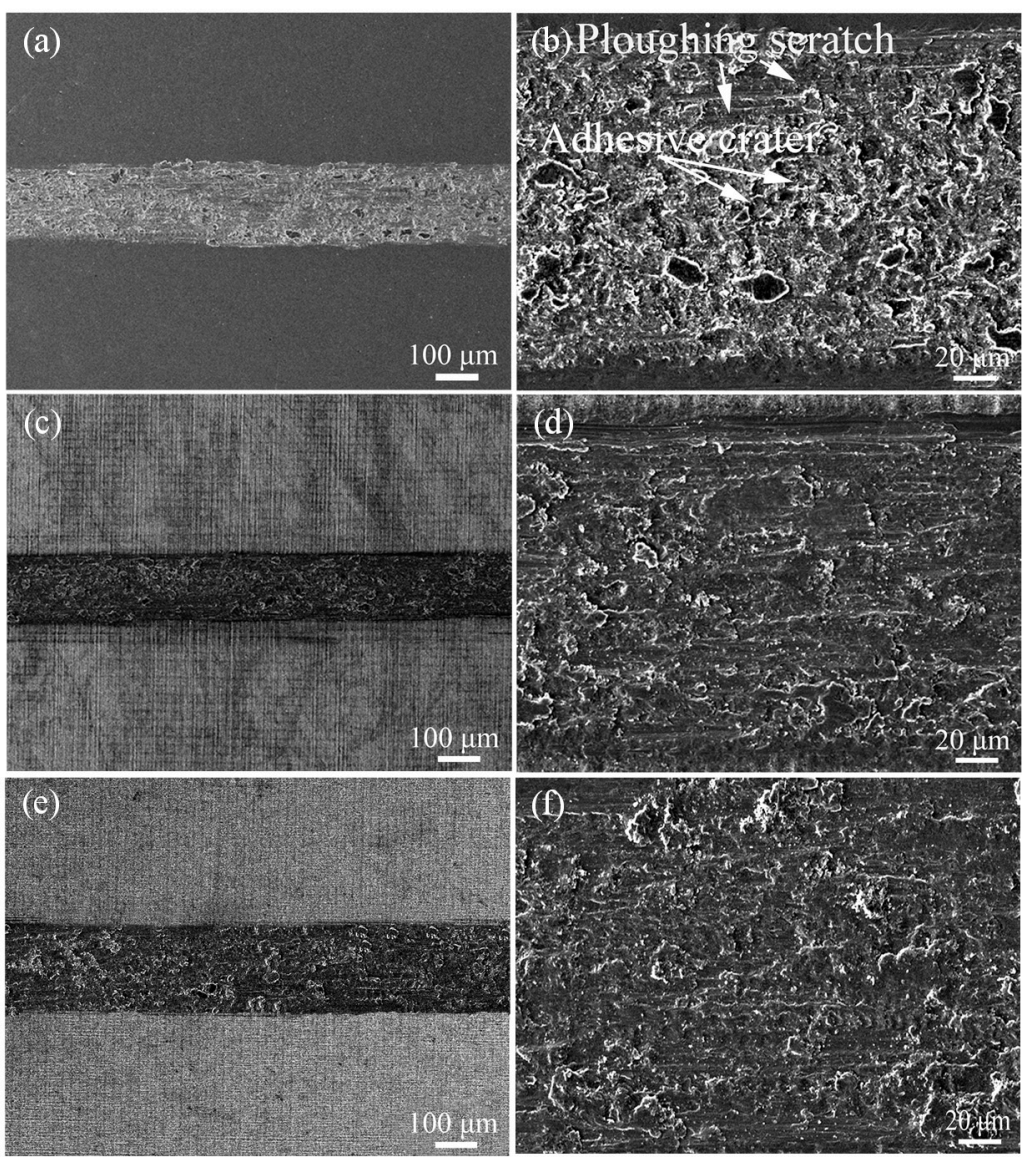

Figure 7. SEM micrographs of the wear tracks under starved oil lubricated conditions. (a,b) Wear tracks of SS; (c,d) Wear tracks of LIPSS-90; (e,f) Wear tracks of LIPSS-0.

\section{Conclusions}

Textured surfaces with LIPSS were produced on AISI 304L steel using a femtosecond laser. Friction and wear tests were performed using reciprocating ball-on-disk tests under dry and starved oil lubricated conditions. The average friction coefficient of LIPSS-90 was obviously lower than that of SS, and the average friction coefficient of LIPSS-0 was slightly reduced compared with SS under the dry condition. This phenomenon can be explained by combined effects of adhesion, trapped wear particles, and asperity deformation. The average friction coefficient of the textured surfaces 
with LIPSS was significantly reduced compared with that of the smooth surface under the starved oil lubricated conditions. This phenomenon can be explained by the combined effects of adhesion, oil reservoirs, and asperity deformation. Consequently, the average friction coefficient can be reduced by fabricating ripple structures on the surface under both dry and starved oil lubricated conditions. Our findings may suggest applications in fields including magnetic storage and microelectromechanical systems (MEMS).

Our future work will further investigate the effect of different LIPSS parameters on tribological properties on both the dry and lubricated conditions

Acknowledgments: This work was financially supported by the National Natural Science Foundation of China (Grant Nos. 61178024 and 11374316) and partially supported by the National Basic Research Program of China (Grant No. 2011CB808103).

Author Contributions: Zhuo Wang and Quanzhong Zhao conceived and designed the research; Zhuo Wang performed the research; Zhuo Wang and Quanzhong Zhao analyzed the data; Chengwei Wang contributed experimental procedures; Zhuo Wang and Quanzhong Zhao wrote the paper.

Conflicts of Interest: The authors declare no conflict of interest.

\section{References}

1. Wan, Y.; Xiong, D.S. The effect of laser surface texturing on frictional performance of face seal. J. Mater. Process. Technol. 2008, 197, 96-100.

2. Wu, Z.; Deng, J.X.; Chen, Y.; Xing, Y.Q.; Zhao, J. Performance of the self-lubricating textured tools in dry cutting of Ti-6Al-4V. Int. J. Adv. Manu. Technol. 2012, 62, 943-951.

3. Bhushan, B. Nanotribology and nanomechanics in nano/biotechnology. Phil. Trans. R. Soc. A 2008, 366, 1499-1537. [CrossRef] [PubMed]

4. Xing, Y.Q.; Deng, J.X.; Wu, Z.; Cheng, H.W. Effect of regular surface textures generated by laser on tribological behavior of $\mathrm{Si}_{3} \mathrm{~N}_{4} / \mathrm{TiC}$ ceramic. Appl. Surf. Sci. 2013, 265, 823-832. [CrossRef]

5. Kovalchenko, A.; Ajayi, O.; Erdemir, A.; Fenske, G.; Etsion, I. The effect of laser texturing of steel surfaces and speed-load parameters on the transition of lubrication regime from boundary to hydrodynamic. Tribol. Trans. 2004, 47, 299-307. [CrossRef]

6. Gualtieri, E.; Borghi, A.; Calabri, L.; Pugno, N.; Valeri, S. Increasing nanohardness and reducing friction of nitride steel by laser surface texturing. Tribol. Int. 2009, 42, 699-705. [CrossRef]

7. Pettersson, U.; Jacobson, S. Textured surfaces for improved lubrication at high pressure and low sliding speed of roller/piston in hydraulic motors. Tribol. Int. 2007, 40, 355-359. [CrossRef]

8. Pettersson, U.; Jacobson, S. Influence of surface texture on boundary lubricated sliding contacts. Tribol. Int. 2003, 36, 857-864. [CrossRef]

9. Wang, X.; Kato, K. Improving the anti-seizure ability of SiC seal in water with RIE texturing. Tribol. Lett. 2002, 14, 275-280. [CrossRef]

10. He, D.Q.; Zheng, S.X.; Pu, J.B.; Zhang, G.G.; Hu, L.T. Improving tribological properties of titanium alloys by combining laser surface texturing and diamond-like carbon film. Tribol. Int. 2015, 82, 20-27. [CrossRef]

11. Tagawa, N.; Takada, M.; Mori, A.; Sawada, H.; Kawahara, K. Development of contact sliders with nanotextures by femtosecond laser processing. Tribol. Lett. 2006, 24, 143-149. [CrossRef]

12. Yasumaru, N.; Miyazaki, K.; Kiuchi, J. Control of tribological properties of diamond-like carbon films with femtosecond-laser-induced nanostructuring. Appl. Surf. Sci. 2008, 254, 2364-2368. [CrossRef]

13. Kawasegi, N.; Sugimori, H.; Morimoto, H.; Morita, N.; Hori, I. Development of cutting tools with microscale and nanoscale textures to improve friction behavior. Precis. Eng. 2009, 33, 248-254. [CrossRef]

14. Wu, B.; Zhou, M.; Li, J.; Ye, X.; Li, G.; Cai, L. Superhydrophobic surfaces fabricated by microstructuring of stainless steel using a femtosecond laser. Appl. Surf. Sci. 2009, 256, 61-66. [CrossRef]

15. Ahsan, M.S.; Ahmed, F.; Kim, Y.G.; Lee, M.S.; Jun, M.B.G. Colorizing stainless steel surface by femtosecond laser induced micro/nano-structures. Appl. Surf. Sci. 2011, 257, 7771-7777. [CrossRef]

16. Chen, C.Y.; Chung, C.J.; Wu, B.H.; Li, W.L.; Chien, C.W.; Wu, P.H.; Cheng, C.W. Microstructure and lubricating property of ultra-fast laser pulse textured silicon carbide seals. Appl. Phys. A 2012, 107, 345-350. [CrossRef] 
17. Eichstädt, J.; Romer, G.R.B.E.; Huis in't Veld, A.J. Towards friction control using laser-induced periodic surface structure. Phys. Proc. 2011, 12, 7-15. [CrossRef]

18. Bonse, J.; Koter, R.; Hartelt, M.; Spaltmann, D.; Pentzien, S.; Hohm, S. Femtosecond laser-induced periodic surface structures on steel and titanium alloy for tribological applications. Appl. Phys. A 2014, 117, 103-110. [CrossRef]

19. Birnbaum, M. Semiconductor surface damage produced by ruby lasers. J. Appl. Phys. 1965, 36, 3688-3689. [CrossRef]

20. Yasumaru, N.; Sentoku, E.; Miyazaki, K.; Kiuchi, J. Femtosecond-laser-induced nanostructure formed on nitrided stainless steel. Appl. Surf. Sci. 2013, 264, 611-615. [CrossRef]

21. Pfeiffer, M.; Engel, A.; Gruettner, H.; Guenther, K.; Marquardt, F.; Reisse, G. Ripple formation in various metals and super-hard tetrahedral amorphous carbon films in consequence of femtosecond laser irradiation. Appl. Phys. A 2013, 110, 655-659. [CrossRef]

22. Zhao, Q.Z.; Malzer, S.; Wang, L.J. Formation of subwavelength periodic structures on tungsten induced by ultrashort laser pulses. Opt. Lett. 2007, 32, 1932-1934. [CrossRef] [PubMed]

23. Bonse, J.; Rosenfeld, A.; Kruger, J. Implication of transient changes of optical and surface properties of solids during femtosecond laser pulse irradiation to the formation of laser-induced periodic surface structures. Appl. Surf. Sci. 2011, 257, 5420-5423. [CrossRef]

24. Shen, M.; Carey, J.; Crouch, C.; Kandyla, M.; Stone, H.; Mazur, E. High-density regular arrays of nanometer-scale rods formed on silicon surfaces via femtosecond laser irradiation in water. Nano Lett. 2008, 8, 2087-2091. [CrossRef] [PubMed]

25. Bian, H.; Yang, Q.; Liu, H.W.; Chen, F.; Du, G.Q.; Si, J.H.; Hou, X. A facile preparation route for netlike microstructures on a stainless steel using an ethanol-mediated femtosecond laser irradition. Mater. Sci. Eng. C 2013, 33, 663-667. [CrossRef] [PubMed]

26. Mannion, P.T.; Magee, J.; Coyne, E.; O'Connor, G.M.; Glynn, T.J. The effect of damage accumulation behavior on ablation thresholds and damage morphology in ultrafast laser micro-machining of common metals in air. Appl. Surf. Sci. 2004, 233, 275-287. [CrossRef]

27. Bizi-bandoki, P.; Valette, S.; Audouard, E.; Benayoun, S. Effect of stationary femtosecond laser irradiation on substructures' formation on a mold stainless steel surface. Appl. Surf. Sci. 2013, 270, 197-204. [CrossRef]

28. Yasumaru, N.; Miyazaki, K.; Kiuchi, J. Femtosecond-laser-induced nanostructure formed on hard thin films of TiN and DLC. Appl. Phys. A 2003, 76, 983-985. [CrossRef]

29. Miyazaki, K.; Maekawa, N.; Kobayashi, W.; Kaku, M.; Yasumaru, N.; Kiuchi, J. Reflectivity in femtosecond-laser-induced structural changes of diamond-like carbon film. Appl. Phys. A 2005, 80, 17-21. [CrossRef]

30. Ardron, M.; Weston, N.; Hand, D. A practical technique for the generation of highly uniform LIPSS. Appl. Surf. Sci. 2014, 313, 123-131. [CrossRef]

31. Sipe, J.E.; Young, J.F.; Preston, J.S.; van Driel, H.M. Laser-induced periodic surface structure. I. Theory. Phys. Rev. B 1983, 27, 1141-1154. [CrossRef]

32. Miyaji, G.; Miyazaki, K. Origin of periodicity in nanostructuring on thin film surfaces ablated with femtosecond laser pulses. Opt. Express 2008, 16, 16265-16271. [CrossRef] [PubMed]

33. Costache, F.; Henyk, M.; Reif, J. Modification of dielectric surfaces with ultra-short laser pulses. Appl. Surf. Sci. 2002, 186, 352-357. [CrossRef]

34. Jia, T.Q.; Chen, H.X.; Huang, M.; Zhao, F.L.; Qiu, J.R.; Li, R.X. Formation of nanogratings on the surface of a ZnSe crystal irradiated by femtosecond laser pulses. Phys. Rev. B. 2005, 72, 1254291-1254294. [CrossRef]

35. Dong, Y.; Molian, P. Coulomb explosion-induced formation of highly oriented nanoparticles on thin films of 3C-SiC by the femtosecond pulsed laser. Appl. Phys. Lett. 2004, 84, 10-12. [CrossRef]

36. Li, K.M.; Yao, Z.Q.; Hu, Y.X.; Gu, W.B. Friction and wear performance of laser peen textured surface under starved lubrication. Tribol. Int. 2014, 77, 97-105. [CrossRef]

37. Qi, L.T.; Nishii, K.; Namba, Y. Regular subwavelength surface structures induced by femtosecond laser pulses on stainless steel. Opt. Lett. 2009, 34, 1846-1848. [CrossRef] [PubMed]

38. Kim, D.E.; Suh, N.P. On microscopic mechanism of friction and wear. Wear 1991, 149, 199-208. [CrossRef]

39. Bathe, R.; Krishna, V.S.; Nikumb, S.K. Laser surface texturing of gray cast iron for improving tribological behavior. Appl. Phys. A 2014, 117, 117-123. [CrossRef] 
40. Dumitru, G.; Romano, V.; Gerbig, Y.; Weber, H.P.; Haefke, H. Femtosecond laser processing of nitride-based thin films to improve their tribological performance. Appl. Phys. A 2005, 80, 283-287. [CrossRef]

41. Xing, Y.Q.; Deng, J.X.; Zhou, Y.H.; Li, S.P. Fabrication and tribological properties of $\mathrm{Al}_{2} \mathrm{O}_{3} / \mathrm{TiC}$ ceramic with nano-textures and $\mathrm{WS}_{2} / \mathrm{Zr}$ soft-coatings. Surf. Coat. Technol. 2014, 258, 699-710. [CrossRef]

42. Rosenkranz, A.; Reinert, L.; Gachot, G.; Mücklich, F. Alignment and wear debris effects between laser-patterned steel surfaces under sliding conditions. Wear 2014, 318, 49-61. [CrossRef]

43. Yu, C.J.; Yu, H.L.; Liu, G.; Chen, W.; He, B.; Wang, Q.J. Understanding topographic dependence of friction with micro- and nano-grooved surfaces. Tribol. Lett. 2014, 53, 145-156. [CrossRef]

44. Vihena, L.M.; Sedlacek, M.; Podgornik, B. Surface texturing by pulsed Nd: YAG laser. Tribol. Int. 2009, 42, 1496-1504. [CrossRef]

45. Shun, P.W.; Zhou, Z.F.; Li, K.Y. Investigation of the tribological properties of the different textured DLC coatings under reciprocating lubricated condition. Tribol. Int. 2013, 65, 259-264. [CrossRef]

(C) 2015 by the authors; licensee MDPI, Basel, Switzerland. This article is an open access article distributed under the terms and conditions of the Creative Commons by Attribution (CC-BY) license (http:/ / creativecommons.org/licenses/by/4.0/). 